\title{
Some coupled fixed point theorems in quasi-partial metric spaces
}

\author{
Wasfi Shatanawi ${ }^{1}$ and Ariana Pitea ${ }^{2^{*}}$
}

\author{
"Correspondence: \\ arianapitea@yahoo.com \\ ${ }^{2}$ Faculty of Applied Sciences, \\ University Politehnica of Bucharest, \\ 313 Splaiul Independenţei, \\ Bucharest, 060042, Romania \\ Full list of author information is \\ available at the end of the article
}

\begin{abstract}
In this paper, we study some coupled fixed point results in a quasi-partial metric space. Also, we introduce some examples to support the useability of our results. MSC: $47 \mathrm{H} 10 ; 54 \mathrm{H} 25$
\end{abstract}

Keywords: partial metric space; quasi-partial metric space; coupled fixed point

\section{Introduction and preliminaries}

In 1994, Matthews [1] introduced the notion of partial metric spaces and extended the Banach contraction principle from metric spaces to partial metric spaces. After that, many fixed point theorems in partial metric spaces have been given by several authors (for example, see [2-29]). Very recently, Haghi et al. [30,31] showed in their interesting paper that some of fixed point theorems in partial metric spaces can be obtained from metric spaces.

Following Matthews [1], the notion of partial metric space is given as follows.

Definition 1.1 [1] A partial metric on a nonempty set $X$ is a function $p: X \times X \rightarrow \mathbb{R}^{+}$such that for all $x, y, z \in X$ :

$$
\begin{aligned}
& \left(\mathrm{p}_{1}\right) \quad x=y \Longleftrightarrow p(x, x)=p(x, y)=p(y, y), \\
& \left(\mathrm{p}_{2}\right) p(x, x) \leq p(x, y), \\
& \left(\mathrm{p}_{3}\right) p(x, y)=p(y, x), \\
& \left(\mathrm{p}_{4}\right) p(x, y) \leq p(x, z)+p(z, y)-p(z, z) .
\end{aligned}
$$

A partial metric space is a pair $(X, p)$ such that $X$ is a nonempty set and $p$ is a partial metric on $X$.

Karapinar et al. [32] introduced the concept of quasi-partial metric spaces and studied some fixed point theorems on quasi-partial metric spaces.

Definition 1.2 [32] A quasi-partial metric on a nonempty set $X$ is a function $q: X \times X \rightarrow$ $\mathbb{R}^{+}$which satisfies:

$\left(\mathrm{QPM}_{1}\right)$ If $q(x, x)=q(x, y)=q(y, y)$, then $x=y$,

$\left(\mathrm{QPM}_{2}\right) q(x, x) \leq q(x, y)$,

$\left(\mathrm{QPM}_{3}\right) q(x, x) \leq q(y, x)$, and

$\left(\mathrm{QPM}_{4}\right) q(x, y)+q(z, z) \leq q(x, z)+q(z, y)$

for all $x, y, z \in X$. 
A quasi-partial metric space is a pair $(X, q)$ such that $X$ is a nonempty set and $q$ is a quasi-partial metric on $X$.

Let $q$ be a quasi-partial metric space on the set $X$. Then

$$
d_{q}(x, y)=q(x, y)+q(y, x)-p(x, x)-p(y, y)
$$

is a metric on $X$.

Definition 1.3 [32] Let $(X, q)$ be a quasi-partial metric space. Then:

(1) A sequence $\left(x_{n}\right)$ converges to a point $x \in X$ if and only if

$$
q(x, x)=\lim _{n \rightarrow \infty} q\left(x, x_{n}\right)=\lim _{n \rightarrow \infty} q\left(x_{n}, x\right) .
$$

(2) A sequence $\left(x_{n}\right)$ is called a Cauchy sequence if $\lim _{n, m \rightarrow \infty} p\left(x_{n}, x_{m}\right)$ and $\lim _{n, m \rightarrow \infty} p\left(x_{n}, x_{m}\right)$ exist (and are finite).

(3) The quasi-partial metric space $(X, q)$ is said to be complete if every Cauchy sequence $\left(x_{n}\right)$ in $X$ converges, with respect to $\tau_{q}$, to a point $x \in X$ such that

$$
q(x, x)=\lim _{n, m \rightarrow \infty} q\left(x_{n}, x_{m}\right)=\lim _{n, m \rightarrow \infty} q\left(x_{m}, x_{n}\right) .
$$

The following lemma is crucial in our work.

Lemma 1.1 [32] Let $(X, q)$ be a quasi-partial metric space. Then the following statements hold true:

(A) If $q(x, y)=0$, then $x=y$.

(B) If $x \neq y$, then $q(x, y)>0$ and $q(y, x)>0$.

Bhaskar and Lakshmikantham [33] introduced the concept of coupled fixed point and studied some nice coupled fixed point theorems. Later, Lakshmikantham and Ćirić [34] introduced the notion of a coupled coincidence point of mappings. For some works on a coupled fixed point, we refer the reader to [35-46].

Definition 1.4 [33] Let $X$ be a nonempty set. We call an element $(x, y) \in X \times X$ a coupled fixed point of the mapping $F: X \times X \rightarrow X$ if

$$
F(x, y)=x \quad \text { and } \quad F(y, x)=y .
$$

Definition 1.5 [34] An element $(x, y) \in X \times X$ is called a coupled coincidence point of the mappings $F: X \times X \rightarrow X$ and $g: X \rightarrow X$ if

$$
F(x, y)=g x \quad \text { and } \quad F(y, x)=g y .
$$

Abbas et al. [47] introduced the concept of $w$-compatible mappings as follows.

Definition 1.6 [47] Let $X$ be a nonempty set. We say that the mappings $F: X \times X \rightarrow X$ and $g: X \rightarrow X$ are $w$-compatible if $g F(x, y)=F(g x, g y)$ whenever $g x=F(x, y)$ and $g y=F(y, x)$. 
In this paper, we study some coupled fixed point theorems in the setting of quasi-partial metric spaces. We introduce some examples to support our results.

\section{The main results}

We start this section with the following coupled fixed point theorem.

Theorem 2.1 Let $(X, q)$ be a quasi-partial metric space, $g: X \rightarrow X$ and $F: X \times X \rightarrow X$ be two mappings. Suppose that there exist $k_{1}, k_{2}$ and $k_{3}$ in $[0,1)$ with $k_{1}+k_{2}+k_{3}<1$ such that the condition

$$
\begin{aligned}
& q\left(F(x, y), F\left(x^{*}, y^{*}\right)\right)+q\left(F(y, x), F\left(y^{*}, x^{*}\right)\right) \\
& \quad \leq k_{1}\left(q\left(g x, g x^{*}\right)+q\left(g y, g y^{*}\right)\right)+k_{2}(q(g x, F(x, y))+q(g y, F(y, x))) \\
& \quad+k_{3}\left(q\left(g x^{*}, F\left(x^{*}, y^{*}\right)\right)+q\left(g y^{*}, F\left(y^{*}, x^{*}\right)\right)\right)
\end{aligned}
$$

holds for all $x, y, x^{*}, y^{*} \in X$. Also, suppose the following hypotheses:

(1) $F(X \times X) \subseteq g X$.

(2) $g(X)$ is a complete subspace of $X$ with respect to the quasi-partial metric $q$.

Then the mappings $F$ and $g$ have a coupled coincidence point $(u, v)$ satisfying $g u=$ $F(u, v)=F(v, u)=g u$.

Moreover, if $F$ and $g$ are w-compatible, then $F$ and $g$ have a unique common fixed point of the form $(u, u)$.

Proof Let $x_{0}, y_{0} \in X$. Since $F(X \times X) \subseteq g X$, we put $g x_{1}=F\left(x_{0}, y_{0}\right)$ and $g y_{1}=F\left(y_{0}, x_{0}\right)$. Again, since $F(X \times X) \subseteq g X$, we put $g x_{2}=F\left(x_{1}, y_{1}\right)$ and $g y_{2}=F\left(y_{1}, x_{1}\right)$. Continuing this process, we can construct two sequences $\left(g x_{n}\right)$ and $\left(g y_{n}\right)$ in $X$ such that

$$
g x_{n}=F\left(x_{n-1}, y_{n-1}\right), \quad \forall n \in \mathbb{N},
$$

and

$$
g y_{n}=F\left(y_{n-1}, x_{n-1}\right), \quad \forall n \in \mathbb{N} .
$$

- Let $n \in \mathbb{N}$. Then by inequality (2.1), we obtain

$$
\begin{aligned}
& q\left(g x_{n}, g x_{n+1}\right)+q\left(g y_{n}, g y_{n+1}\right) \\
&= q\left(F\left(x_{n-1}, y_{n-1}\right), F\left(x_{n}, y_{n}\right)\right)+q\left(F\left(y_{n-1}, x_{n-1}\right), F\left(y_{n}, x_{n}\right)\right) \\
& \leq k_{1}\left(q\left(g x_{n-1}, g x_{n}\right)+q\left(g y_{n-1}, g y_{n}\right)\right) \\
&+k_{2}\left(q\left(g x_{n-1}, F\left(x_{n-1}, y_{n-1}\right)\right)+q\left(g y_{n-1}, F\left(y_{n-1}, x_{n-1}\right)\right)\right) \\
&+k_{3}\left(q\left(g x_{n}, F\left(x_{n}, y_{n}\right)\right)+q\left(g y_{n}, F\left(y_{n}, x_{n}\right)\right)\right) \\
&= k_{1}\left(q\left(g x_{n-1}, g x_{n}\right)+q\left(g y_{n-1}, g y_{n}\right)\right)+k_{2}\left(q\left(g x_{n-1}, g x_{n}\right)+q\left(g y_{n-1}, g y_{n}\right)\right) \\
&+k_{3}\left(q\left(g x_{n}, g x_{n+1}\right)+q\left(g y_{n}, g y_{n+1}\right)\right) .
\end{aligned}
$$

From (2.2), we have

$$
q\left(g x_{n}, g x_{n+1}\right)+q\left(g y_{n}, g y_{n+1}\right) \leq \frac{k_{1}+k_{2}}{1-k_{3}}\left(q\left(g x_{n-1}, g x_{n}\right)+q\left(g y_{n-1}, g y_{n}\right)\right) .
$$


Put $k=\frac{k_{1}+k_{2}}{1-k_{3}}$. Then $k<1$. Repeating (2.3) $n$-times, we get

$$
q\left(g x_{n}, g x_{n+1}\right)+q\left(g y_{n}, g y_{n+1}\right) \leq k^{n}\left(q\left(g x_{0}, g x_{1}\right)+q\left(g y_{0}, g y_{1}\right)\right) .
$$

Let $m$ and $n$ be natural numbers with $m>n$. Then

$$
\begin{aligned}
q\left(g x_{n}, g x_{m}\right)+q\left(g y_{n}, g y_{m}\right) & \leq \sum_{i=n}^{m-1} q\left(g x_{i}, g x_{i+1}\right)+q\left(g y_{i}, g y_{i+1}\right) \\
& \leq \sum_{i=n}^{m-1} k^{i}\left(q\left(g x_{0}, g x_{1}\right)+q\left(g y_{0}, g y_{1}\right)\right) \\
& \leq \frac{k^{n}}{1-k}\left(q\left(g x_{0}, g x_{1}\right)+q\left(g y_{0}, g y_{1}\right)\right) .
\end{aligned}
$$

Letting $n, m \rightarrow+\infty$, we get

$$
\lim _{n, m \rightarrow+\infty} q\left(g x_{n}, g x_{m}\right)=\lim _{n, m \rightarrow+\infty} q\left(g y_{n}, g y_{m}\right)=0 .
$$

- By similar arguments as above, we can show that

$$
\lim _{n, m \rightarrow+\infty} q\left(g x_{m}, g x_{n}\right)=\lim _{n, m \rightarrow+\infty} q\left(g y_{m}, g y_{n}\right)=0 .
$$

Thus the sequences $\left(g x_{n}\right)$ and $\left(g y_{n}\right)$ are Cauchy in $(g X, q)$. Since $(g X, q)$ is complete, there are $u$ and $v$ in $X$ such that $g x_{n} \rightarrow g u$ and $g y_{n} \rightarrow g y$ with respect to $\tau_{q}$, that is,

$$
\begin{aligned}
q(g u, g u) & =\lim _{n \rightarrow+\infty} q\left(g u, g x_{n}\right)=\lim _{n \rightarrow+\infty} q\left(g x_{n}, g u\right) \\
& =\lim _{n, m \rightarrow+\infty} q\left(g x_{m}, g x_{n}\right)=\lim _{n, m \rightarrow+\infty} q\left(g x_{n}, g x_{m}\right)
\end{aligned}
$$

and

$$
\begin{aligned}
q(g v, g v) & =\lim _{n \rightarrow+\infty} q\left(g v, g y_{n}\right)=\lim _{n \rightarrow+\infty} q\left(g y_{n}, g v\right) \\
& =\lim _{n, m \rightarrow+\infty} q\left(g y_{m}, g y_{n}\right)=\lim _{n, m \rightarrow+\infty} q\left(g y_{n}, g y_{m}\right) .
\end{aligned}
$$

From (2.5) and (2.6), we have

$$
\begin{aligned}
q(g u, g u) & =\lim _{n \rightarrow+\infty} q\left(g u, g x_{n}\right)=\lim _{n \rightarrow+\infty} q\left(g x_{n}, g u\right) \\
& =\lim _{n, m \rightarrow+\infty} q\left(g x_{m}, g x_{n}\right)=\lim _{n, m \rightarrow+\infty} q\left(g x_{n}, g x_{m}\right)=0
\end{aligned}
$$

and

$$
\begin{aligned}
q(g v, g v) & =\lim _{n \rightarrow+\infty} q\left(g v, g y_{n}\right)=\lim _{n \rightarrow+\infty} q\left(g y_{n}, g v\right) \\
& =\lim _{n, m \rightarrow+\infty} q\left(g y_{m}, g y_{n}\right)=\lim _{n, m \rightarrow+\infty} q\left(g y_{n}, g y_{m}\right)=0 .
\end{aligned}
$$


For $n$ in $\mathbb{N}$, we obtain

$$
\begin{aligned}
q\left(g x_{n+1}, F(u, v)\right) & \leq q\left(g x_{n+1}, g u\right)+q(g u, F(u, v))-q(g u, g u) \\
& \leq q\left(g x_{n+1}, g u\right)+q(g u, F(u, v)) \\
& \leq q\left(g x_{n+1}, g u\right)+q\left(g u, g x_{n+1}\right)+q\left(g x_{n+1}, F(u, v)\right)-q\left(g x_{n+1}, g x_{n+1}\right) \\
& \leq q\left(g x_{n+1}, g u\right)+q\left(g u, g x_{n+1}\right)+q\left(g x_{n+1}, F(u, v)\right) .
\end{aligned}
$$

On letting $n \rightarrow+\infty$ in the above inequalities and using (2.7) and (2.8), we have

$$
\lim _{n \rightarrow+\infty} q\left(g x_{n+1}, F(u, v)\right)=q(g u, F(u, v)) .
$$

Similarly, we have

$$
\lim _{n \rightarrow+\infty} q\left(g y_{n+1}, F(v, u)\right)=q(g v, F(v, u)) .
$$

- We show that $g u=F(u, v)$ and $g v=F(v, u)$.

For $n \in \mathbb{N}$, we have

$$
\begin{aligned}
q\left(g x_{n+1}, F(u, v)\right)+q\left(g y_{n+1}, F(v, u)\right) \\
=q\left(F\left(x_{n}, y_{n}\right), F(u, v)\right)+q\left(F\left(y_{n}, x_{n}\right), F(v, u)\right) \\
\leq k_{1}\left(q\left(g x_{n}, g u\right)+q\left(g y_{n}, g v\right)\right)+k_{2}\left(q\left(g x_{n}, F\left(x_{n}, y_{n}\right)\right)+q\left(g y_{n}, F\left(y_{n}, x_{n}\right)\right)\right. \\
\quad+k_{3}(q(g u, F(u, v))+q(g v, F(v, u))) \\
\left.=k_{1}\left(q\left(g x_{n}, g u\right)+q\left(g y_{n}, g v\right)\right)+k_{1}\left(q\left(g x_{n}, g x_{n+1}\right)\right)+q\left(g y_{n}, g y_{n+1}\right)\right) \\
\quad+k_{3}(q(g u, F(u, v))+q(g v, F(v, u))) .
\end{aligned}
$$

Letting $n \rightarrow+\infty$ in above inequalities and using (2.9)-(2.10), we get

$$
q(g u, F(u, v))+q(g v, F(v, u)) \leq k_{3}(q(g u, F(u, v))+q(g v, F(v, u))) .
$$

Since $k_{3}<1$, we get $q(g u, F(u, v))=q(g v, F(v, u))=0$. By Lemma 1.1, we get $g u=F(u, v)$ and $g v=F(v, u)$. Next, we will show that $g u=g v$. Now, from (2.1) we have

$$
\begin{aligned}
& q(g u, g v)+q(g v, g u) \\
&= q(F(u, v), F(v, u))+q(F(v, u), F(u, v)) \\
& \leq k_{1}(q(g u, g v)+q(g v, g u))+k_{2}(q(g u, F(u, v))+q(g v, F(v, u))) \\
& \quad+k_{3}(q(g v, F(v, u))+q(g u, F(u, v))) \\
&= k_{1}(q(g u, g v)+q(g v, g u))+k_{2}(q(g u, g u)+q(g v, g v))+k_{3}(q(g v, g v)+q(g u, g u)) .
\end{aligned}
$$

Using (2.7) and (2.8), we obtain

$$
q(g u, g v)+q(g v, g u) \leq k_{1}(q(g u, g v)+q(g v, g u)) .
$$


Since $k_{1}<1$, we have $q(g u, g v)=q(g v, g u)=0$ By Lemma 1.1, we get that $g u=g v$. Finally, assume that $g$ and $F$ are $w$-compatible. Let $u_{1}=g u$ and $v_{1}=g v$. Then

$$
g u_{1}=g g u=g(F(u, v))=F(g u, g v)=F\left(u_{1}, v_{1}\right)
$$

and

$$
g v_{1}=g g v=g(F(v, u))=F(g v, g u)=F\left(v_{1}, u_{1}\right) .
$$

From (2.11) and (2.12), we can show that

$$
q\left(g u_{1}, g u_{1}\right)=q\left(g v_{1}, g v_{1}\right) .
$$

- We claim that $g u_{1}=g u$ and $g v_{1}=g v$.

From (2.1), we have

$$
\begin{aligned}
& q\left(g u_{1}, g u\right)+q\left(g v_{1}, g v\right) \\
&= q\left(F\left(u_{1}, v_{1}\right), F(u, v)\right)+q\left(F\left(v_{1}, u_{1}\right), F(v, u)\right) \\
& \leq k_{1}\left(q\left(g u_{1}, g u\right)+q\left(g v_{1}, g v\right)\right)+k_{2}\left(q\left(g u_{1}, F\left(u_{1}, v_{1}\right)\right)+q\left(g v_{1}, F\left(v_{1}, u_{1}\right)\right)\right) \\
&+k_{3}(q(g u, F(u, v))+q(g v, F(v, u))) \\
&= k_{1}\left(q\left(g u_{1}, g u\right)+q\left(g v_{1}, g v\right)\right)+k_{2}\left(q\left(g u_{1}, g u_{1}\right)+q\left(g v_{1}, g v_{1}\right)\right) \\
&+k_{3}(q(g u, g u)+q(g v, g v)) \\
&= k_{1}\left(q\left(g u_{1}, g u\right)+q\left(g v_{1}, g v\right)\right) .
\end{aligned}
$$

Since $k_{1}<1$, we conclude that $q\left(g u_{1}, g u\right)=q\left(g v_{1}, g v\right)=0$. By Lemma 1.1, we get $g u_{1}=g u$ and $g v_{1}=g v$. Therefore $u_{1}=g u_{1}$ and $v_{1}=g v_{1}$. Again, since $g u=g v$, we get $u_{1}=v_{1}$. Hence $F$ and $g$ have a unique common coupled fixed point of the form $(u, u)$.

Corollary 2.1 Let $(X, q)$ be a quasi-partial metric space, $g: X \rightarrow X$ and $F: X \times X \rightarrow X$ be two mappings. Suppose that there exist $a, b, c, d, e, f$ in $[0,1)$ with $a+b+c+d+e+f<1$ such that

$$
\begin{aligned}
& q\left(F(x, y), F\left(x^{*}, y^{*}\right)\right) \\
& \quad \leq a q\left(g x, g x^{*}\right)+b q\left(g y, g y^{*}\right)+c q(g x, F(x, y))+d q(g y, F(y, x)) \\
& \quad+e q\left(g x^{*}, F\left(x^{*}, y^{*}\right)\right)+f q\left(g y^{*}, F\left(y^{*}, x^{*}\right)\right)
\end{aligned}
$$

holds for all $x, y, x^{*}, y^{*} \in X$. Also, suppose the following hypotheses:

(1) $F(X \times X) \subseteq g X$.

(2) $g(X)$ is a complete subspace of $X$ with respect to the quasi-partial metric $q$.

Then $F$ and $g$ have a coupled coincidence point $(u, v)$ satisfying $g u=F(u, v)=F(v, u)=g u$. Moreover, if $F$ and $g$ are w-compatible, then $F$ and $g$ have a unique common fixed point of the form $(u, u)$. 
Proof Given $x, y, x^{*}, y^{*} \in X$. From (2.13), we have

$$
\begin{aligned}
& q\left(F(x, y), F\left(x^{*}, y^{*}\right)\right) \\
& \quad \leq a q\left(g x, g x^{*}\right)+b q\left(g y, g y^{*}\right)+c q(g x, F(x, y))+d q(g y, F(y, x)) \\
& \quad+e q\left(g x^{*}, F\left(x^{*}, y^{*}\right)\right)+f q\left(g y^{*}, F\left(y^{*}, x^{*}\right)\right)
\end{aligned}
$$

and

$$
\begin{aligned}
& q\left(F(y, x), F\left(y^{*}, x^{*}\right)\right) \\
& \quad \leq a q\left(g y, g y^{*}\right)+b q\left(g x, g x^{*}\right)+c q(g y, F(y, x))+d q(g x, F(x, y)) \\
& \quad+e q\left(g y^{*}, F\left(y^{*}, x^{*}\right)\right)+f q\left(g x^{*}, F\left(x^{*}, y^{*}\right)\right) .
\end{aligned}
$$

Adding inequality (2.14) to inequality (2.15), we get

$$
\begin{aligned}
& q\left(F(x, y), F\left(x^{*}, y^{*}\right)\right)+q\left(F(y, x), F\left(y^{*}, x^{*}\right)\right) \\
& \quad \leq(a+b)\left(q\left(g x, g x^{*}\right)+q\left(g y, g y^{*}\right)\right)+(c+d)(q(g x, F(x, y))+q(g y, F(y, x))) \\
& \quad+(e+f)\left(q\left(g x^{*}, F\left(x^{*}, y^{*}\right)\right)+q\left(g y^{*}, F\left(y^{*}, x^{*}\right)\right)\right) .
\end{aligned}
$$

Thus, the result follows from Theorem 2.1.

Corollary 2.2 Let $(X, q)$ be a quasi-partial metric space, let $g: X \rightarrow X$ and $F: X \times X \rightarrow X$ be two mappings. Suppose that there exists $k \in[0,1)$ with $k_{1}+k_{2}+k_{3}<1$ such that

$$
q\left(F(x, y), F\left(x^{*}, y^{*}\right)\right)+q\left(F(y, x), F\left(y^{*}, x^{*}\right)\right) \leq k\left(q\left(g x, g x^{*}\right)+q\left(g y, g y^{*}\right)\right)
$$

holds for all $x, y, x^{*}, y^{*} \in X$. Also, suppose the following hypotheses:

(1) $F(X \times X) \subseteq g X$.

(2) $g(X)$ is a complete subspace of $X$ with respect to the quasi-partial metric $q$.

Then $F$ and $g$ have a coupled coincidence point $(u, v)$ satisfying $g u=F(u, v)=F(v, u)=g u$.

Moreover, if $F$ and $g$ are w-compatible, then $F$ and $g$ have a unique common fixed point of the form $(u, u)$.

Corollary 2.3 Let $(X, q)$ be a quasi-partial metric space, $g: X \times X$ and $F: X \times X \rightarrow X$ be two mappings. Suppose that there exists $k \in[0,1)$ with $k<1$ such that

$$
q\left(F(x, y), F\left(x^{*}, y^{*}\right)\right)+q\left(F(y, x), F\left(y^{*}, x^{*}\right)\right) \leq k(q(g x, F(x, y))+q(g y, F(y, x)))
$$

holds for all $x, y, x^{*}, y^{*} \in X$. Also, suppose the following hypotheses:

(1) $F(X \times X) \subseteq X$.

(2) $g(X)$ is a complete subspace of $X$ with respect to the quasi-partial metric $q$.

Then $F$ and $g$ have a coupled coincidence point $(u, v)$ satisfying $g u=F(u, v)=F(v, u)=g u$.

Moreover, if $F$ and $g$ are w-compatible, then $F$ and $g$ have a unique common fixed point of the form $(u, u)$. 
Corollary 2.4 Let $(X, q)$ be a quasi-partial metric space, $g: X \rightarrow X$ and $F: X \times X \rightarrow X$ be two mappings. Suppose that there exists $k \in[0,1)$ with $k<1$ such that

$$
q\left(F(x, y), F\left(x^{*}, y^{*}\right)\right)+q\left(F(y, x), F\left(y^{*}, x^{*}\right)\right) \leq k\left(q\left(g x^{*}, F\left(x^{*}, y^{*}\right)\right)+q\left(g y^{*}, F\left(y^{*}, x^{*}\right)\right)\right)
$$

holds for all $x, y, x^{*}, y^{*} \in X$. Also, suppose the following hypotheses:

(1) $F(X \times X) \subseteq g X$.

(2) $g(X)$ is a complete subspace of $X$ with respect to the quasi-partial metric $q$.

Then $F$ and $g$ have a coupled coincidence point $(u, v)$ satisfying $g u=F(u, v)=F(v, u)=g u$.

Moreover, if $F$ and $g$ are w-compatible, then $F$ and $g$ have a unique common fixed point of the form $(u, u)$.

Let $g=I_{X}$ (the identity mapping) in Theorem 2.2 and Corollaries 2.1-2.4. Then we have the following results.

Corollary 2.5 Let $(X, q)$ be a quasi-partial metric space and let $F: X \times X \rightarrow X$ be a mapping. Suppose that there exist $k_{1}, k_{2}, k_{3} \in[0,1)$ with $k_{1}+k_{2}+k_{3}<1$ such that

$$
\begin{aligned}
& q\left(F(x, y), F\left(x^{*}, y^{*}\right)\right)+g\left(F(y, x), F\left(y^{*}, x^{*}\right)\right) \\
& \quad \leq k_{1}\left(q\left(x, x^{*}\right)+q\left(y, y^{*}\right)\right)+k_{2}(q(x, F(x, y))+q(y, F(y, x))) \\
& \quad+k_{3}\left(q\left(x^{*}, F\left(x^{*}, y^{*}\right)\right)+q\left(y^{*}, F\left(y^{*}, x^{*}\right)\right)\right)
\end{aligned}
$$

holds for all $x, y, x^{*}, y^{*} \in X$.

Then $F$ has a unique coupled fixed point of the form $(u, u)$.

Corollary 2.6 Let $(X, q)$ be a quasi-partial metric space and let $F: X \times X \rightarrow X$ be a mapping. Suppose that there exist $a, b, c, d, e, f \in[0,1)$ with $a+b+c+d+e+f<1$ such that

$$
\begin{aligned}
& q\left(F(x, y), F\left(x^{*}, y^{*}\right)\right) \\
& \quad \leq a q\left(x, x^{*}\right)+b q\left(y, y^{*}\right)+c q(x, F(x, y))+d q(y, F(y, x)) \\
& \quad+e q\left(x^{*}, F\left(x^{*}, y^{*}\right)\right)+f q\left(y^{*}, F\left(y^{*}, x^{*}\right)\right)
\end{aligned}
$$

holds for all $x, y, x^{*}, y^{*} \in X$.

Then $F$ has a unique coupled fixed point of the form $(u, u)$.

Corollary 2.7 Let $(X, q)$ be a complete quasi-partial metric space and let $F: X \times X \rightarrow X$ be a mapping. Suppose that there exists $k \in[0,1)$ such that

$$
q\left(F(x, y), F\left(x^{*}, y^{*}\right)\right)+q\left(F(y, x), F\left(y^{*}, x^{*}\right)\right) \leq k\left(q\left(x, x^{*}\right)+q\left(y, y^{*}\right)\right)
$$

holds for all $x, y, x^{*}, y^{*} \in X$.

Then $F$ has a unique coupled fixed point of the form $(u, u)$. 
Corollary 2.8 Let $(X, q)$ be a complete quasi-partial metric space and let $F: X \times X \rightarrow X$ be a mapping. Suppose that there exists $k \in[0,1)$ with $k<1$ such that

$$
q\left(F(x, y), F\left(x^{*}, y^{*}\right)\right)+q\left(F(y, x), F\left(y^{*}, x^{*}\right)\right) \leq k(q(x, F(x, y))+q(y, F(y, x)))
$$

holds for all $x, y, x^{*}, y^{*} \in X$.

Then $F$ has a unique coupled fixed point of the form $(u, u)$.

Corollary 2.9 Let $(X, q)$ be a complete quasi-partial metric space and let $F: X \times X \rightarrow X$ be a mapping. Suppose that there exists $k \in[0,1)$ with $k<1$ such that

$$
q\left(F(x, y), F\left(x^{*}, y^{*}\right)\right)+q\left(F(y, x), F\left(y^{*}, x^{*}\right)\right) \leq k\left(q\left(x^{*}, F\left(x^{*}, y^{*}\right)\right)+q\left(y^{*}, F\left(y^{*}, x^{*}\right)\right)\right)
$$

holds for all $x, y, x^{*}, y^{*} \in X$.

Then $F$ has a unique coupled fixed point of the form $(u, u)$.

Theorem 2.2 Let $(X, q)$ be a complete quasi-partial metric space and let $F: X \times X \rightarrow X$, $g: X \rightarrow X$ be two mappings. Suppose that there exists a function $\phi: g X \rightarrow \mathbb{R}_{+}$such that

$$
q(g x, F(x, y))+q(g y, F(y, x)) \leq \phi(g x)+\phi(g y)-\phi(F(x, y))-\phi(F(y, x))
$$

holds for all $(x, y) \in X \times X$. Also, assume that the following hypotheses are satisfied:

(a) $F(X \times X) \subset g X$;

(b) if $G: X \times X \rightarrow \mathbb{R}, G(x, y)=q(F(x, y), g x)$, then for each sequence $\left(g x_{n}, g y_{n}\right) \rightarrow(u, v)$, we have $G(u, v) \leq k \liminf _{n \rightarrow \infty} G\left(x_{n}, y_{n}\right)$ for some $k>0$.

Then $F$ and $g$ have a coupled coincidence point $(u, v)$. In addition, $q(g u, g u)=0$ and $q(g v, g v)=0$.

Proof Consider $\left(x_{0}, y_{0}\right) \in X \times X$. As $F(X \times X) \subset g X$, there are $x_{1}$ and $y_{1}$ from $X$ such that $g x_{1}=F\left(x_{0}, y_{0}\right)$ and $g y_{1}=F\left(y_{0}, x_{0}\right)$. By repeating this process, we construct two sequences, $\left(x_{n}\right)$ and $\left(y_{n}\right)$ with $g x_{n+1}=F\left(x_{n}, y_{n}\right)$ and $g y_{n+1}=F\left(y_{n}, x_{n}\right)$.

The fourth property of the quasi-partial metric space gives us

$$
\begin{aligned}
& q\left(g x_{n}, g x_{n+2}\right)+q\left(g y_{n}, g y_{n+2}\right) \\
& \quad \leq q\left(g x_{n}, g x_{n+1}\right)+q\left(g x_{n+1}, g x_{n+2}\right) \\
& \quad-q\left(g x_{n+1}, g x_{n+1}\right)+q\left(g y_{n}, g y_{n+1}\right)+q\left(g y_{n+1}, g y_{n+2}\right)-q\left(g y_{n+1}, g y_{n+1}\right) \\
& \leq \\
& \leq q\left(g x_{n}, g x_{n+1}\right)+q\left(g x_{n+1}, g x_{n+2}\right)+q\left(g y_{n}, g y_{n+1}\right)+q\left(g y_{n+1}, g y_{n+2}\right) .
\end{aligned}
$$

Based on the above inequality, for $m>n$, we obtain

$$
\begin{aligned}
q\left(g x_{n}, g x_{m}\right)+q\left(g y_{n}, g y_{m}\right) & \leq \sum_{k=n}^{m-1}\left[q\left(g x_{k}, g x_{k+1}\right)+q\left(g y_{k}, g y_{k+1}\right)\right] \\
& =\sum_{k=n}^{m-1}\left[q\left(g x_{k}, F\left(x_{k}, y_{k}\right)\right)+q\left(g y_{k}, F\left(y_{k}, x_{k}\right)\right)\right]
\end{aligned}
$$




$$
\begin{aligned}
& \leq \sum_{k=n}^{m-1}\left[\phi\left(g x_{k}\right)+\phi\left(g y_{k}\right)-\phi\left(F\left(x_{k}, y_{k}\right)\right)-\phi\left(F\left(y_{k}, x_{k}\right)\right)\right] \\
& =\sum_{k=n}^{m-1}\left[\phi\left(g x_{k}\right)+\phi\left(g y_{k}\right)-\phi\left(g x_{k+1}\right)-\phi\left(g y_{k+1}\right)\right] \\
& =\phi\left(g x_{n}\right)+\phi\left(g y_{n}\right)-\phi\left(g x_{m}\right)-\phi\left(g y_{m}\right) .
\end{aligned}
$$

Consider $S_{n}(x)=\sum_{k=0}^{n}\left[q\left(g x_{k}, g x_{k+1}\right)+q\left(g y_{k}, g y_{k+1}\right)\right]$. Inequality (2.17) implies that

$$
S_{n}(x) \leq \phi\left(g x_{0}\right)+\phi\left(g y_{0}\right)
$$

hence the nondecreasing sequence $\left\{S_{n}\right\}$ is bounded, so it is convergent. Taking the limit as $n, m \rightarrow+\infty$ in (2.16), we conclude that

$$
\lim _{n, m \rightarrow+\infty} q\left(g x_{n}, g x_{m}\right)=\lim _{n, m \rightarrow+\infty} q\left(g y_{n}, g y_{m}\right) .
$$

Using similar arguments, it can be proved that

$$
\lim _{n, m \rightarrow \infty} q\left(g x_{m}, g x_{n}\right)=\lim _{n, m \rightarrow \infty} q\left(g y_{m}, g y_{n}\right)=0 .
$$

As $\left(g x_{n}\right)$ and $\left(g y_{n}\right)$ are Cauchy sequences in the complete quasi-partial metric space $(X, q)$, there are $u, v$ in $X$ such that $u=\lim _{n \rightarrow \infty} g x_{n}$ and $v=\lim _{n \rightarrow \infty} g v_{n}$. Having in mind hypothesis (b), the following relations hold true:

$$
\begin{aligned}
0 & \leq q(F(u, v), g u)=G(u, v) \leq k \liminf _{n \rightarrow \infty} G\left(x_{n}, y_{n}\right) \\
& =k \liminf _{n \rightarrow \infty} q\left(F\left(x_{n}, y_{n}\right), g x_{n}\right) \\
& =k \liminf _{n \rightarrow \infty} q\left(g x_{n+1}, g x_{n}\right) \\
& =0 .
\end{aligned}
$$

We get $q(F(u, v), g u)=0$, and by Lemma 1.1, it follows that $F(u, v)=g(u)$.

Analogously, it can be proved that $F(v, u)=g \nu$.

As a conclusion, we have obtained that $(u, v)$ is a coupled coincidence point of the mappings $F$ and $g$, and $q(g u, g u)=0, q(g \nu, g v)=0$.

Corollary 2.10 Let $(X, q)$ be a complete quasi-partial metric space and let $F: X \times X \rightarrow X$ be a mapping. Suppose that there exists a function $\phi: X \rightarrow \mathbb{R}_{+}$such that

$$
q(x, F(x, y))+q(y, F(y, x)) \leq \phi(x)+\phi(y)-\phi(F(x, y))-\phi(F(y, x))
$$

holds for all $(x, y) \in X \times X$. Also, assume that the following hypotheses are satisfied:

(a) $F(X \times X) \subset X$

(b) if $G: X \times X \rightarrow \mathbb{R}, G(x, y)=q(F(x, y), x)$, then for each sequence $\left(x_{n}, y_{n}\right) \rightarrow(u, v)$, we have $G(u, v) \leq k \liminf _{n \rightarrow \infty} G\left(x_{n}, y_{n}\right)$ for some $k>0$.

Then $F$ has a coupled coincidence point $(u, v)$. In addition, $q(u, u)=0$ and $q(v, v)=0$.

Proof Follows from Theorem 2.2 by taking $g=I_{X}$ (the identity mapping). 


\section{Examples}

Now, we introduce some examples to support our results.

Example 3.1 On the set $X=[0,1]$, define

$q: X \times X \rightarrow \mathbb{R}^{+}, \quad q(x, y)=|x-y|+x$.

Also, define

$$
F: X \times X \rightarrow X, \quad F(x, y)= \begin{cases}\frac{1}{4}(x-y), & x \geq y \\ 0, & x<y\end{cases}
$$

and $g: X \rightarrow X$ by $g x=\frac{1}{2} x$. Then

(1) $(X, q)$ is a complete quasi-partial metric space.

(2) $F(X \times X) \subseteq g X$.

(3) For any $x, y, x^{*}, y^{*} \in X$, we have

$$
q\left(F(x, y), F\left(x^{*}, y^{*}\right)\right)+q\left(F(y, x), F\left(y^{*}, x^{*}\right)\right) \leq \frac{1}{2}\left(q\left(g x, g x^{*}\right)+q\left(g y, g y^{*}\right)\right) .
$$

Proof The proofs of (1) and (2) are clear. To prove (3), we consider the following cases.

Case 1: $x<y$ and $x^{*}<y^{*}$. Here we have

$$
F(x, y)=0, \quad F\left(x^{*}, y^{*}\right)=0, \quad F(y, x)=\frac{y-x}{4}, \quad F\left(y^{*}, x^{*}\right)=\frac{y^{*}-x^{*}}{4} .
$$

Therefore

$$
\begin{aligned}
q & \left(F(x, y), F\left(x^{*}, y^{*}\right)\right)+q\left(F(y, x), F\left(y^{*}, x^{*}\right)\right) \\
& =q(0,0)+q\left(\frac{x-y}{4}, \frac{y^{*}-x^{*}}{4}\right) \\
& =\frac{1}{4}\left|(y-x)-\left(y^{*}-x^{*}\right)\right|+\frac{1}{4}(y-x) \\
& \leq \frac{1}{2}\left|\left(\frac{1}{2} y-\frac{1}{2} x\right)-\left(\frac{1}{2} y^{*}-\frac{1}{2} x^{*}\right)\right|+\frac{1}{2}\left(\frac{1}{2} y-\frac{1}{2} x\right) \\
& \leq \frac{1}{2}\left|\left(\frac{1}{2} x^{*}-\frac{1}{2} x\right)-\left(\frac{1}{2} y^{*}-\frac{1}{2} y\right)\right|+\frac{1}{2}\left(\frac{1}{2} y+\frac{1}{2} x\right) \\
& \leq \frac{1}{2}\left(\left|\frac{1}{2} x^{*}-\frac{1}{2} x\right|+\frac{1}{2} x+\left|\frac{1}{2} y^{*}-\frac{1}{2} y\right|+\frac{1}{2} y\right) \\
& =\frac{1}{2}\left(\left|g x^{*}-g x\right|+g x+\left|g y-g y^{*}\right|+g y\right) \\
& =\frac{1}{2}\left(q\left(g x, g x^{*}\right)+q\left(g y, g y^{*}\right)\right) .
\end{aligned}
$$

Case 2: $x<y$ and $x^{*} \geq y^{*}$. Here we have

$$
F(x, y)=0, \quad F\left(x^{*}, y^{*}\right)=\frac{x^{*}-y^{*}}{4}, \quad F(y, x)=\frac{y-x}{4}
$$


and $F\left(y^{*}, x^{*}\right)=0$. Therefore

$$
\begin{aligned}
q( & \left.F(x, y), F\left(x^{*}, y^{*}\right)\right)+q\left(F(y, x), F\left(y^{*}, x^{*}\right)\right) \\
& =q\left(0, \frac{x^{*}-y^{*}}{4}\right)+q\left(\frac{y-x}{4}, 0\right) \\
& =\frac{1}{4}\left|0-\left(x^{*}-y^{*}\right)\right|+\frac{1}{4}|y-x|+\frac{1}{4}(y-x) \\
& =\frac{1}{4}\left(x^{*}-y^{*}\right)+\frac{1}{4}(y-x)+\frac{1}{4}(y-x) \\
& =\frac{1}{2}\left(\left(\frac{1}{2} x^{*}-\frac{1}{2} x\right)-\frac{1}{2} x+\left(\frac{1}{2} y-\frac{1}{2} y^{*}\right)+\frac{1}{2} y\right) \\
& \leq \frac{1}{2}\left(\left(\frac{1}{2} x^{*}-\frac{1}{2} x\right)+\frac{1}{2} x+\left(\frac{1}{2} y-\frac{1}{2} y^{*}\right)+\frac{1}{2} y\right) \\
& \leq \frac{1}{2}\left(\left|\frac{1}{2} x^{*}-\frac{1}{2} x\right|+\frac{1}{2} x+\left|\frac{1}{2} y^{*}-\frac{1}{2} y\right|+\frac{1}{2} y\right) \\
& =\frac{1}{2}\left(\left|g x^{*}-g x\right|+g x+\left|g y-g y^{*}\right|+g y\right) \\
& =\frac{1}{2}\left(q\left(g x, g x^{*}\right)+q\left(g y, g y^{*}\right)\right) .
\end{aligned}
$$

Case 3: $x>y$ and $x^{*}<y^{*}$. Using similar arguments to those given in Case (2), we can show that

$$
q\left(F(x, y), F\left(x^{*}, y^{*}\right)\right)+q\left(F(y, x), F\left(y^{*}, x^{*}\right)\right) \leq \frac{1}{2}\left(q\left(g x, g x^{*}\right)+q\left(g y, g y^{*}\right)\right) .
$$

Case 4: $x \geq y$ and $x^{*} \geq y^{*}$. Using similar arguments to those given in Case (1), we can show that

$$
q\left(F(x, y), F\left(x^{*}, y^{*}\right)\right)+q\left(F(y, x), F\left(y^{*}, x^{*}\right)\right) \leq \frac{1}{2}\left(q\left(g x, g x^{*}\right)+q\left(g y, g y^{*}\right)\right) .
$$

Thus $F$ and $g$ satisfy all the hypotheses of Corollary 2.7. So, $F$ and $g$ have a unique common fixed point. Here $(0,0)$ is the unique common fixed point of $F$ and $g$.

We end with an example related to Theorem 2.2.

Example 3.2 Let $X=[0,+\infty)$. Define

$$
q: X \times X \rightarrow \mathbb{R}^{+}, \quad q(x, y)=|x-y|+x .
$$

Also, define

$$
\begin{aligned}
& F: X \times X \rightarrow X, \quad F(x, y)=x ; \quad g: X \rightarrow X, \\
& g x=2 x ; \quad \phi: X \rightarrow \mathbb{R}^{+}, \quad \phi(x)=2 x .
\end{aligned}
$$

Then:

(1) $(X, q)$ is a complete quasi-partial metric space. 
(2) $F(X \times X) \subseteq g X$.

(3) For any $x, y \in X$, we have

$$
q(g x, F(x, y))+q(g y, F(y, x)) \leq \phi(g x)+\phi(g y)-\phi(F(x, y))-\phi(F(y, x)) .
$$

(4) Let $G: X \times X \rightarrow \mathbb{R}^{+}$be defined by $G(x, y)=q(F(x, y), g x)$. If $\left(g x_{n}\right)$ and $\left(g y_{n}\right)$ are two sequences in $X$ with $\left(g x_{n}, g y_{n}\right) \rightarrow(u, v)$, then $G(u, v) \leq 4 \liminf _{n \rightarrow+\infty} G\left(x_{n}, y_{n}\right)$.

Proof The proofs of (1) and (2) are clear. To prove (3) given $x, y \in X, g x=2 x, g y=2 y$, $F(x, y)=x, F(y, x)=y, \phi(x)=2 x$ and $\phi(y)=2 y$. Thus

$$
\begin{aligned}
q(g x, F(x, y))+q(g y, F(y, x)) & =q(2 x, x)+q(2 y, y) \\
& =2 x+2 y \\
& \leq 4 x+4 y-2 x-2 y \\
& =\phi(2 x)+\phi(2 y)-\phi(x)-\phi(y) \\
& =\phi(g x)+\phi(g y)-\phi(F(x, y))-\phi(F(y, x)) .
\end{aligned}
$$

To prove (4), let $\left(g x_{n}\right)$ and $\left(g y_{n}\right)$ be two sequences in $X$ such that $\left(g x_{n}, g y_{n}\right) \rightarrow(u, v)$ for some $u, v \in X$. Then $g x_{n} \rightarrow u$ and $g y_{n} \rightarrow v$. Thus

$$
q\left(g x_{n}, u\right)=q\left(2 x_{n}, u\right) \rightarrow q(u, u)
$$

and

$$
q\left(u, g x_{n}\right)=q\left(u, 2 x_{n}\right) \rightarrow q(u, u) .
$$

Therefore

$$
\left|2 x_{n}-u\right|+2 x_{n} \rightarrow u
$$

and

$$
\left|u-2 x_{n}\right|+u \rightarrow u .
$$

Therefore

$$
\left|u-2 x_{n}\right| \rightarrow 0 .
$$

Hence $x_{n} \rightarrow \frac{1}{2} u$ in $\mathbb{R}^{+}$. Now

$$
\begin{aligned}
G(u, v) & =q(F(u, v), u) \\
& =q(u, u) \\
& =u \\
& \leq 4\left(\frac{1}{2} u\right)
\end{aligned}
$$




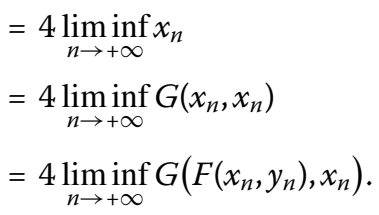

So, $F$ and $g$ satisfy all the hypotheses of Theorem 2.2. Hence $F$ and $g$ have a coupled coincidence point. Here $(0,0)$ is the coupled coincidence point of $F$ and $g$.

Competing interests

The authors declare that they have no competing interests.

\section{Authors' contributions}

Both authors contributed equally and significantly in writing this article. Both authors read and approved the final manuscript.

\section{Author details}

${ }^{1}$ Department of Mathematics, Hashemite University, Zarqa, Jordan. ${ }^{2}$ Faculty of Applied Sciences, University Politehnica of Bucharest, 313 Splaiul Independenţei, Bucharest, 060042, Romania.

Received: 16 March 2013 Accepted: 24 May 2013 Published: 11 June 2013

\section{References}

1. Matthews, SG: Partial metric topology. In: General Topology and Its Applications. Proc. 8th Summer Conf., Queen's College 1992. Ann. N. Y. Acad. Sci., vol. 728, pp. 183-197 (1994)

2. Abdeljawad, T, Karapinar, E, Taş, K: Existence and uniqueness of a common fixed point on partial metric spaces. Appl. Math. Lett. 24(11), 1900-1904 (2011)

3. Abdeljawad, T, Karapinar, E, Taş, K: A generalized contraction principle with control functions on partial metric spaces. Comput. Math. Appl. 63(3), 716-719 (2012)

4. Abdeljawad, T: Fixed points for generalized weakly contractive mappings in partial metric spaces. Math. Comput. Model. 54(11-12), 2923-2927 (2011)

5. Altun, I, Erduran, A: Fixed point theorems for monotone mappings on partial metric spaces. Fixed Point Theory Appl. 2011, Article ID 508730 (2011)

6. Altun, I, Simsek, H: Some fixed point theorems on dualistic partial metric spaces. J. Adv. Math. Stud. 1(1-2), 1-8 (2008)

7. Altun, I, Simsek, H: Some fixed point theorems on ordered metric spaces and application. Fixed Point Theory Appl. 2010, Article ID 6214469 (2010)

8. Altun, I, Sola, F, Simsek, H: Generalized contractions on partial metric spaces. Topol. Appl. 157(18), 2778-2785 (2010)

9. Altun, I, Sadarangani, K: Corrigendum to "Generalized contractions on partial metric spaces" [Topology Appl. 157 (2010) 2778-2785]. Topol. Appl. 158(13), 1738-1740 (2011)

10. Aydi, H: Some fixed point results in ordered partial metric spaces. J. Nonlinear Sci. Appl. 4(2), 1-12 (2011)

11. Aydi, H: Some coupled fixed point results on partial metric spaces. Int. J. Math. Math. Sci. 2011, Article ID 647091 (2011)

12. Aydi, H: Fixed point theorems for generalized weakly contractive condition in ordered partial metric spaces. J. Nonlinear Anal. Optim. Theory Appl. 2(2), 33-48 (2011)

13. Aydi, H, Karapinar, E, Shatanawi, W: Coupled fixed point results for $(\psi, \varphi)$-weakly contractive condition in ordered partial metric spaces. Comput. Math. Appl. 62, 4449-4460 (2011)

14. Ćirić, L, Samet, B, Aydi, H, Vetro, C: Common fixed points of generalized contractions on partial metric spaces and an application. Appl. Math. Comput. 218, 2398-2406 (2011)

15. Golubović, Z, Kadelburg, Z, Radenović, S: Coupled coincidence points of mappings in ordered partial metric spaces. Abstr. Appl. Anal. 2012, Article ID 192581 (2012)

16. Karapınar, E, Erhan, I: Fixed point theorems for operators on partial metric spaces. Appl. Math. Lett. 24, 1894-1899 (2011)

17. Nashine, HK, Kadelburg, Z, Radenović, S: Common fixed point theorems for weakly isotone increasing mappings in ordered partial metric spaces. Math. Comput. Model. 57, 2355-2365 (2013)

18. Oltra, S, Valero, O: Banach's fixed point theorem for partial metric spaces. Rend. Ist. Mat. Univ. Trieste 36(1-2), 17-26 (2004)

19. Romaguera, S: A Kirk type characterization of completeness for partial metric spaces. Fixed Point Theory Appl. 2010 Article ID 493298 (2010)

20. Romaguera, S: Fixed point theorems for generalized contractions on partial metric spaces. Topol. Appl. 159, 194-199 (2012)

21. Samet, B, Rajović, M, Lazović, R, Stoiljković, R: Common fixed point results for nonlinear contractions in ordered partial metric spaces. Fixed Point Theory Appl. 2011, 71 (2011)

22. Shatanawi, W, Nashine, HK: A generalization of Banach's contraction principle for nonlinear contraction in a partial metric space. J. Nonlinear Sci. Appl. 5, 37-43 (2012)

23. Shatanawi, W, Nashine, HK, Tahat, N: Generalization of some coupled fixed point results on partial metric spaces. Int. J. Math. Math. Sci. 2012, Article ID 686801 (2012) 
24. Shatanawi, W, Samet, B, Abbas, M: Coupled fixed point theorems for mixed monotone mappings in ordered partial metric spaces. Math. Comput. Model. 55, 680-687 (2012)

25. Shatanawi, W, Postolache, $\mathrm{M}$ : Coincidence and fixed point results for generalized weak contractions in the sense of Berinde on partial metric spaces. Fixed Point Theory Appl. 2013, Article ID 54 (2013)

26. Radenović, S: Remarks on some coupled fixed point results in partial metric spaces. Nonlinear Funct. Anal. Appl. 18(1), 39-50 (2013)

27. Nashine, HK, Kadelburg, Z, Radenović, S: Fixed point theorems via various cyclic contractive conditions in partial metric spaces. Publ. Inst. Math. (Belgr.) 93(107), 69-93 (2013)

28. Valero, O: On Banach fixed point theorems for partial metric spaces. Appl. Gen. Topol. 6(2), 229-240 (2005)

29. Altun, I, Acar, Ö: Fixed point theorems for weak contractions in the sense of Berinde on partial metric spaces. Topol. Appl. 159, 2642-2648 (2012)

30. Haghi, RH, Rezapour, Sh, Shahzad, N: Be careful on partial metric fixed point results. Topol. Appl. 160, 450-454 (2013)

31. Haghi, RH, Rezapour, S, Shahzad, N: Some fixed point generalizations are not real generalizations. Nonlinear Anal. 74, 1799-1803 (2011)

32. Karapinar, E, Erhan, I, Öztürk, A: Fixed point theorems on quasi-partial metric spaces. Math. Comput. Model. (2012). doi:10.1016/j.mcm.2012.06.036

33. Bhaskar, TG, Lakshmikantham, V: Fixed point theorems in partially ordered metric spaces and applications. Nonlinear Anal. 65, 1379-1393 (2006)

34. Lakshmikantham, V, Ćirić, L: Coupled fixed point theorems for nonlinear contractions in partially ordered metric spaces. Nonlinear Anal. 70, 4341-4349 (2009)

35. Cho, YJ, Rhoades, BE, Saadati, R, Samet, B, Shatanawi, W: Nonlinear coupled fixed point theorems in ordered generalized metric spaces with integral type. Fixed Point Theory Appl. 2012, 8 (2012)

36. Choudhury, BS, Maity, P: Coupled fixed point results in generalized metric spaces. Math. Comput. Model. 54, 73-79 (2011)

37. Choudhury, BS, Metiya, N, Postolache, M: A generalized weak contraction principle with applications to coupled coincidence point problems. Fixed Point Theory Appl. (submitted)

38. Karapinar, E: Couple fixed point theorems for nonlinear contractions in cone metric spaces. Comput. Math. Appl. 59 3656-3668 (2010)

39. Samet, B: Coupled fixed point theorems for a generalized Meir-Keeler contraction in partially ordered metric spaces. Nonlinear Anal. 72, 4508-4517 (2010)

40. Sedghi, S, Altun, I, Shobe, N: Coupled fixed point theorems for contractions in fuzzy metric spaces. Nonlinear Anal. 72, 1298-1304 (2010)

41. Shatanawi, W, Samet, B, Abbas, M: Coupled fixed point theorems for mixed monotone mappings in ordered partial metric spaces. Math. Comput. Model. 55, 680-687 (2012)

42. Shatanawi, W: On w-compatible mappings and common coupled coincidence point in cone metric spaces. Appl. Math. Lett. 25, 925-931 (2012)

43. Aydi, H, Postolache, M, Shatanawi, W: Coupled fixed point results for $(\psi, \phi)$-weakly contractive mappings in ordered G-metric spaces. Comput. Math. Appl. 63(1), 298-309 (2012)

44. Radenović, S: Remarks on some recent coupled coincidence point results in symmetric G-metric spaces. J. Operators 2013, Article ID 290525 (2013). doi:10.1155/2013/290525

45. Radenović, S: Remarks on some coupled coincidence point result in partially ordered metric spaces. Arab J. Math. Sci. (2013). doi:10.1016/j.ajmsc.2013.02.003

46. Shatanawi, W: Fixed point theorems for nonlinear weakly C-contractive mappings in metric spaces. Math. Comput. Model. (2011). doi:10.1016/j.mcm.2011.06.069

47. Abbas, M, Khan, MA, Radenović, S: Common coupled fixed point theorems in cone metric spaces for $w$-compatible mapping. Appl. Math. Comput. 217(1), 195-202 (2010)

doi:10.1186/1687-1812-2013-153

Cite this article as: Shatanawi and Pitea: Some coupled fixed point theorems in quasi-partial metric spaces. Fixed Point Theory and Applications 2013 2013:153.

\section{Submit your manuscript to a SpringerOpen ${ }^{\circ}$ journal and benefit from:}

- Convenient online submission

Rigorous peer review

- Immediate publication on acceptance

- Open access: articles freely available online

- High visibility within the field

- Retaining the copyright to your article 